\title{
miRNA-374 Regulates Dexamethasone-induced Differentiation of Primary Cultures of Porcine Adipocytes
}

Authors

Affiliation

\author{
S. Pan, Y. Zheng, R. Zhao, X. Yang
}

Key Laboratory of Animal Physiology and Biochemistry, Nanjing Agricultural University, Nanjing 210095, P. R. China

\author{
Key words \\ - miRNAs \\ - C/EBP- $\beta$ \\ porcine adipocyte \\ - dexamethasone
}

received 27.11.2012

accepted 31.01.2013

\section{Bibliography}

DOI http://dx.doi.org/

10.1055/s-0033-1334896

Published online:

March 6, 2013

Horm Metab Res 2013;

45: 518-525

(c) Georg Thieme Verlag KG Stuttgart · New York

ISSN 0018-5043

\section{Correspondence}

\section{Yang}

Key Laboratory of Animal Physiology and Biochemistry Nanjing Agricultural University Nanjing 210095

P. R. China

Tel.: + 86/25/8439 9020

Fax: + 86/25/84398669

xiaojingyang2000@yahoo.

com.cn

\section{Abstract \\ $\nabla$}

To investigate the effect of glucocorticoid on adipocytes metabolism and miRNAs that may be involved in adipocyte differentiation, primary porcine preadipocytes were treated with $10^{-6}$ M dexamethasone and RU486 (a glucocorticoid receptor antagonist) for $48 \mathrm{~h}$. PPAR- $\gamma$ (peroxisome proliferators-activated receptor- $\gamma$ ), and C/EBP- $\beta$ (CCTTA enhancer binding protein- $\beta$ ) gene and protein expression were measured. The expressions of miRNAs predicted to directly target $\mathrm{C} / \mathrm{EBP}-\beta$ were determined, and the functions of the potential miRNAs were verified. The results showed that the triglyceride content in cultured adipocytes increased significantly after $10^{-6} \mathrm{M}$ dexamethasone treatment for $48 \mathrm{~h}$, whereas the cell viability did not differ among the 4 groups (Control: $10^{-6} \mathrm{M}$ dexamethasone; 10 ${ }^{-6} \mathrm{M}$ RU486: $10^{-6} \mathrm{M}$ dexamethasone $+10^{-6}$ M RU486) $(p>0.05)$. Cells treated with dex-

\section{Introduction}

$\nabla$

Glucocorticoids are well known as stress hormones that show rapid increases after stress, and it has been confirmed to have critical and complex functions during triglyceride (TG) metabolism. Depending on the physiological state, glucocorticoids have been proposed to be both adipogenic and lipolytic in their actions within adipose tissue [1-5]. Therefore, understanding their effects on the regulation of adipose tissue metabolism is critical in determining the correlation between stress and obesity. Although a number of studies about the influence of glucocorticoids on lipid metabolism has been reported [6-8], the specific mechanism of glucocorticoids on lipid metabolism is still largely unknown. Previous studies have shown that adipogenesis is regulated by various adipogenic transcription fac- amethasone for $48 \mathrm{~h}$ significantly upregulated perilipin and PPAR- $\gamma$ gene expression, and PPAR- $\gamma$ protein expression was also significantly increased. However, C/EBP- $\beta$ mRNA and protein expression levels were significantly decreased. Both miR-374a and miR-374b, targeting the C/ EBP- $\beta$ 3'-UTR (3'-untranslated region), were significantly increased. Dual luciferase activity assay results indicated that miR-374a/b was directly recognised and bound to the 3'-UTR of $C / E B P-\beta$ and thereby suppressed $C / E B P-\beta$ gene expression. The present study showed that $10^{-6}$ M dexamethasone promotes lipid accumulation in primary cultures of porcine preadipocytes. PPAR- $\gamma$ and C/EBP- $\beta$ protein abundance showed differences after $48 \mathrm{~h}$ dexamethasone treatment; miR-374a/b may be involved in regulating of $\mathrm{C} /$ EBP- $\beta$ expression. These results provide new targets for further regulation of porcine lipid metabolism. tors, such as C/EBPs (CCTTA enhancer binding protein), PPARs (peroxisome proliferators-activated receptor), HSL (hormone sensitive lipase), and FAS (fatty acid synthase), which are expressed as a transcriptional cascade that promotes adipocyte differentiation, ultimately leading to the mature adipocyte phenotype [9]. The PPAR and C/ EBP family are considered to be the master regulators of adipogenesis, despite other transcription factors positively or negatively regulate adipogenesis [10]. The PAT protein family is the main protein family expressed on the surface of lipid droplets, and perilipin wraps the surface of lipid droplets in mature fat cells [11]. The degree of adipocyte differentiation can be determined by the expression level of perilipin. How these genes mediate glucocorticoid action on lipid metabolism, and whether miRNAs (microRNAs) can be involved during the process is unclear. 
MiRNAs are an emerging class of highly conserved, endogenously expressed noncoding small RNAs (usually 19-25 nucleotides long) that are involved in the post-transcriptional regulation of gene expression by targeting mRNAs, leading to mRNA degradation or translation inhibition [12,13]. miRNA expression is often tissue specific and developmentally regulated [14]. In recent years, accumulated evidences have shown that miRNAs are aberrantly expressed in fat tissue and play a vital role as a novel class of genes related to adipocyte differentiation and lipid metabolism [15, 16]. miR-335 levels are closely correlated with the expression levels of adipocyte differentiation markers, such as PPAR- $\gamma$, aP2 (adipocyte protein 2 ) and FAS in 3T3-L1 adipocytes [17]. miR-378/378* overexpression in ST2 mesenchymal precursor cells increases the size of lipid droplets due to the increased expression of PPAR- $\gamma 2$. At present, 306 mature miRNAs have been identified in Sus scrofa (www.miRbase.org.com), yet the function of most miRNAs is still unknown. Therefore, in the present study, we treated primary culture of porcine preadipocytes with dexamethasone to investigate the influence of glucocorticoid on adipocyte maturation and identify specific roles of the miRNAs involved in this process. The study will further clarify the regulatory mechanism of glucocorticoid on adipocyte differentiation, and provide a new light for further regulation of porcine lipid metabolism.

\section{Materials and Methods \\ $\nabla$}

\section{Primary culture of porcine preadipocyte}

Meishan piglets aged 35 days were killed by exsanguination in a manner approved by the Nanjing Agricultural University Institutional Animal Care and Use Committee. Porcine preadipocytes from 5 piglets were isolated according to published protocols $[18,19]$ with the following modifications and pooled together. Subcutaneous adipose tissue was collected from the neck and back of the piglets and rinsed with serum-free DMEM/F-12 medium (Dulbecco's Modified Eagle Medium: Nutrient Mixture F-12) supplemented with $15 \mathrm{mM} \mathrm{NaHCO}, 100 \mathrm{IU} / \mathrm{ml}$ penicillin, and $100 \mathrm{IU} / \mathrm{ml}$ streptomycin. The tissue mass was cut with scissors into fine pieces and digested with type IV collagenase (GIBCO) (Invitrogen Life Technologies, Carlsbad, CA, USA) (DMEM/F-12+20 g/l BSA $+1 \mathrm{~g} / 1$ type IV collagenase) at $37^{\circ} \mathrm{C}$ in a shaking water bath for approximately $1 \mathrm{~h}$. Then, DMEM/F-12 medium (Invitrogen) containing 10\% fetal bovine serum (FBS) (Invitrogen) was added to stop digestion. The solution was filtered through sterile nylon meshes $(150 \mu \mathrm{m}$ pore size, $75 \mu \mathrm{m}$ pore size, $38 \mu \mathrm{m}$ pore size, and $23 \mu \mathrm{m}$ pore size) to remove undigested tissue. The filtrate was centrifuged at $1000 \mathrm{rpm}$ for $10 \mathrm{~min}$ to separate the floating adipocyte cells from the pellet of porcine preadipocytes. The preadipocytes were then incubated with erythrocyte lysis buffer $\left(0.154 \mathrm{M} \mathrm{NH}_{4} \mathrm{Cl}, 10 \mathrm{mM} \mathrm{KHCO}_{3}\right.$, and $0.1 \mathrm{mM}$ EDTA) at room temperature for $10 \mathrm{~min}$ [20], followed by centrifugation at $800 \mathrm{rpm}$ for $5 \mathrm{~min}$. The preadipocytes pellet was washed with DMEM/F-12, centrifuged, and resuspended in plating medium (20\% FBS, DMEM/F-12). Finally, the preadipocytes were seeded in culture plates at a density of $3 \times 10^{5}$ cells/ $\mathrm{cm}^{2}$ and cultured at $37^{\circ} \mathrm{C}$ in a humidified atmosphere containing $5 \% \mathrm{CO}_{2}$. The medium was changed every second day.

\section{Adipogenic differentiation of preadipocytes}

Cultured preadipocytes were maintained in plating medium until $85-90 \%$ confluence. Then, to induce differentiation, the cultures were exposed to medium (without FBS) containing ITS $(5 \mathrm{U} / \mathrm{ml}$ insulin, $5 \mu \mathrm{g} / \mathrm{ml}$ transferring, and $5 \mathrm{ng} / \mathrm{ml}$ selenium; Sigma, St. Louis, MO, USA), $400 \mu \mathrm{M}$ oleic acid (Sigma), and BSA (Invitrogen) for $48 \mathrm{~h}$, with a $6: 1$ ratio of oleic acid to BSA. All cells were divided into 4 groups (control; $10^{-6} \mathrm{M}$ dexamethasone; $10^{-6} \mathrm{M}$ RU486; $10^{-6} \mathrm{M}$ dexamethasone and $10^{-6} \mathrm{M}$ RU486). RU486 (Sigma) served as glucocorticoid receptor antagonist. In this experiment, a single dose of dexamethasone $\left(10^{-6} \mathrm{M}\right)$ and a single treatment period $(48 \mathrm{~h})$ were adopted which is based on our preliminary experiment. All preadipocytes were cultured in DMEM/F-12 (Invitrogen) plus l-glutamine, penicillin (100 IU/ $\mathrm{ml})$, streptomycin $(100 \mathrm{IU} / \mathrm{ml})$, and fungizone $(4 \mu \mathrm{g} / \mathrm{ml})$ at $37^{\circ} \mathrm{C}$ with $5 \% \mathrm{CO}_{2}$.

\section{MTT assay}

For cell viability studies, preadipocytes were seeded in 96-well culture plates at a density of $10^{3} /$ well, and then, $100 \mu \mathrm{l}$ DMEM/F-12 medium containing $10 \%$ FBS was added to each well. After treatment with $10^{-6} \mathrm{M}$ of dexamethasone for $48 \mathrm{~h}$, the old culture medium was removed, $20 \mu \mathrm{l}$ of MTT (Keygentec, Nanjing, China) was added to each well of the 96-well assay plate containing $100 \mu \mathrm{l}$ of fresh culture medium, and the cells were cultured for $4 \mathrm{~h}$ at $37^{\circ} \mathrm{C}$ in a humidified, $5 \% \mathrm{CO}_{2}$ atmosphere. Afterwards, the absorbance at $490 \mathrm{~nm}$ was recorded using a 96 -well plate reader. The viable cell number is proportional to the absorbance value.

\section{TG content determination}

The intracellular TG content was measured according to the method of Oil Red-O staining extraction. Preadipocytes were seeded in 24-well culture plates until $85-90 \%$ confluence. After treatment with $10^{-6} \mathrm{M}$ of dexamethasone for $48 \mathrm{~h}$, the old culture medium was removed. Cells were first washed with phosphate buffered saline (PBS) for 3 times, fixed with 10\% formalin for $5 \mathrm{~min}$, and changed with fixative for $2 \mathrm{~h}$. After fixation, $60 \%$ isopropanol ( $1 \mathrm{ml} /$ hole) was added to the plate for $30 \mathrm{~s}$. After removing 60\% isopropanol, Oil Red-O working solution (Sunshinebio, Nanjing, China) was added to the plate for $1 \mathrm{~h}(1 \mathrm{ml} /$ well). And then, Oil Red-O working solution was removed and $300 \mu 100 \%$ isopropanol was added to the plate to extract Oil Red-O. Finally, $100 \%$ isopropanol was collected and the plate was observed under a microscope. A wavelength of $510 \mathrm{~nm}$ absorbance was used with a Microplate reader (Synergy BioTek, Vermont, USA), which can reflect the intracellular TG content $[21,22]$.

\section{RNA extraction and real-time PCR}

Total RNA was extracted from homogenised adipose cells using the TRIzol Total RNA Kit (Invitrogen) and subsequently purified with the RNase-Free DNase Set (Promega, Madison, WI, USA) according to the manufacturer's instructions. The total RNA concentration was then quantified by measuring the absorbance at $260 \mathrm{~nm}$ in an Eppendorf BioPhotometer (Gene Company Ltd., Shanghai, China). The absorption ratios $(260 / 280 \mathrm{~nm})$ for all the preparations were between 1.8 and 2.0. Two micrograms of total RNA were reverse transcribed in a final volume of $25 \mu$ with M-MLV reverse transcriptase (Promega) and random hexamer primers (Sunshinebio, Nanjing, China). Reverse transcription was performed in a Thermal Cycler PTC0200 (Bio-Rad, Philadelphia, PA, USA).

Real-time PCR was performed in an Mx 3000P (Agilent Technologies, Stratagene, Santa Clara, CA, USA) with specific primers. All 


\begin{tabular}{|c|c|c|c|}
\hline Target & GenBank accession & PCR products (bp) & Primer sequences \\
\hline \multirow[t]{2}{*}{ Perilipin } & AY973170 & 119 & F: 5'-gcctgactttgctggatgg-3' \\
\hline & & & R: 5'-cttggtgctggtgtaggtcttct-3' \\
\hline \multirow[t]{2}{*}{ PPAR-y } & NM138711 & 210 & F:5'-gcccttcaccactgttgatt-3' \\
\hline & & & R:5'-gagttggaaggctcttcgtg-3' \\
\hline \multirow[t]{2}{*}{ C/EBP- $\beta$} & NM005194 & 158 & F: 5'-gacaagcacagcgacgagta-3' \\
\hline & & & R: 5'-agctgctccaccttcttctg-3' \\
\hline \multirow[t]{2}{*}{ GR } & AY779185 & 108 & F: $5^{\prime}$-ccaaactctgccttgtgtgttc-3' \\
\hline & & & R: 5'-tgtgctgtccttccactgct-3' \\
\hline \multirow[t]{2}{*}{ FAS } & EF589048 & 206 & F: 5'-gtcctgctgaagcctaactc-3' \\
\hline & & & R: 5'-tccttggaaccgtctgtg-3' \\
\hline \multirow[t]{2}{*}{ 18S rRNA } & AY265350 & 122 & F: 5'-cccacggaatcgagaaagag-3' \\
\hline & & & R: 5'-ttgacggaagggcacca-3' \\
\hline
\end{tabular}

Table 1 List of gene specific primers used for q-PCR.

\begin{tabular}{|ll}
\hline microRNA (mature) & Accession \\
\hline miRNA-155 & MIMAT0017953 \\
\hline miRNA-455 & MIMAT0013880 \\
miRNA-423-5p & MIMAT0013960 \\
\hline miRNA-374a & MIMAT0013913 \\
\hline miRNA-374b-5p & MIMAT0013915 \\
\hline miRNA-191 & MIMAT0013876 \\
\hline miRNA-362 & MIMAT0017958 \\
\hline E5 (external reference) & \\
\hline Common downstream primer & \\
\hline Reverse transcription primer &
\end{tabular}

\begin{tabular}{l} 
Chromosome \\
13 \\
12 \\
1 \\
\\
13 \\
\hline
\end{tabular}

\section{Primer sequence $\left(5^{\prime}-3^{\prime}\right)$}

uccuacauguuagcauuaaca ugaggggcagagagcgagacuuu gcaguccaugggcauauacac uuauaauacaaccugauaagug auauaauacaaccugcuaagug caacggaaucccaaaagcagcug aauccuuggaaccuaggugugagug gtgacccacgatgtgtattcgc tagagtgagtgtagcgagca tagagtgagtgtagcgagcacagaattaatacga ctcactatagg $(\mathrm{t})_{16} \mathrm{vn}$

qRT-PCR: quantitative reverse transcription polymerase chain reaction

primers were designed and synthesised by Takara Biotechnology (China; Table 1). The results were expressed relative to the number of $18 \mathrm{~S}$ transcripts used as an internal control. Mock reverse transcription and no template controls (NTC) were used to monitor possible contaminations with genomic DNA. Pooled samples, made by mixing equal cDNA quantities from each sample, were used for optimising the PCR conditions and generating the standard curves for each target gene. The quality of the PCR products was checked by $1.4 \%$ agarose gel electrophoresis. In all cases, single bands of the expected size were observed. Melting curve analyses further assessed the specificity of each PCR product.

\section{Bioinformatics method}

The miRNA targets predicted by computer-aided algorithms were obtained from miRGen (http://www.diana.pcbi.upenn. edu/miRGen.html) [23], TargetScan (http://www.targetscan. org/vert_42/) [24], PicTar (http://pictar.org/) [25], and miRanda (http://www.microrna.org/microrna/).

\section{miRNA real-time PCR quantification}

RT-PCR analysis of miRNA expression was performed in an Mx 3000P (Stratagene) with specific primers ( Table 2). Briefly, total RNA was extracted from adipocytes using TRIZOL Reagent (Invitrogen) and subsequently purified with the RNase-Free DNase Set (Promega) according to the manufacturer's instructions. The treated total RNA $(4 \mu \mathrm{g})$ was polyadenylated by poly(A) polymerase (PAP) at $37^{\circ} \mathrm{C}$ for $1 \mathrm{~h}$ in a $20 \mu$ reaction mixture following the manufacturer's directions for the Poly(A) Tailing Kit (AM1350, Ambion, USA) [26]. The tailing reactions contained $4 \mu \mathrm{g}$ of RNA samples $(1 \mu \mathrm{g} / \mu \mathrm{l}), 4 \mu \mathrm{l}$ of $5 \times \mathrm{E}$-PAP buffer, $2 \mu \mathrm{l}$ of $25 \mathrm{mM} \mathrm{MnCl}_{2}, 2 \mu \mathrm{l}$ of $10 \mathrm{mM}$ ATP, $0.8 \mu \mathrm{l}$ of E-PAP, and the external controls (E1, E2, and E5) at $0.2 \mathrm{pmol}$ each; this reaction solution was then brought up to a $20 \mu \mathrm{l}$ final volume with nuclease-free water. After phenol-chloroform extraction and ethanol precipitation, the RNAs were dissolved in DEPC-treated water and cDNAs were synthesised from tailing RNAs using a gene-specific oligo dT-adapter primer $(1 \mu \mathrm{g} / \mu \mathrm{l})$. Reverse transcriptase reactions contained $2 \mu \mathrm{g}$ poly-A tailed RNAs and $1 \mu \mathrm{l}$ of oligo dTadapter $(1 \mu \mathrm{g} / \mu \mathrm{l})$. The $10 \mu \mathrm{l}$ reactions were incubated for $5 \mathrm{~min}$ at $70{ }^{\circ} \mathrm{C}$ (RT1). The RT2 reactions consisted of the entire RT1 reactions, mixed with $5 \mu \mathrm{l} \mathrm{M-MLV} 5 \times$ buffer (containing $250 \mathrm{mM} \mathrm{pH}$ 8.3 Tris- $\mathrm{HCl}, 15 \mathrm{mM} \mathrm{MgCl}_{2}, 375 \mathrm{mM} \mathrm{KCl}$, and $\left.50 \mathrm{mM} \mathrm{DTT}\right), 1.25 \mu \mathrm{l}$

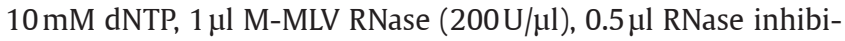
tor $(40 \mathrm{U} / \mu \mathrm{l})$. The $25 \mu \mathrm{l}$ reactions were incubated at $42^{\circ} \mathrm{C}$ for $1 \mathrm{~h}$ and then at $95^{\circ} \mathrm{C}$ for $5 \mathrm{~min}$. The $25 \mu \mathrm{l} \mathrm{PCR}$ reactions included $2 \mu \mathrm{l}$ RT product, $2 \mu$ l primers ( $\bullet$ Table 2 ), $8.5 \mu$ l sterile triple distilled $\mathrm{H}_{2} \mathrm{O}$, and $12.5 \mu \mathrm{l}$ SYBR Premix Ex Taq TM (TaKaRa, Tokyo, Japan). The reactions were incubated in a 96 -well optical plate at $95^{\circ} \mathrm{C}$ for $5 \mathrm{~min}$, followed by 28 cycles at $95^{\circ} \mathrm{C}$ for $30 \mathrm{~s}$ and $66^{\circ} \mathrm{C}$ for $30 \mathrm{~s}$. The PCR reactions run on an Mx 3000P (Agilent Technologies) and analysed using the Mx 3000P System SDS software.

E5 small nuclear RNA was used as an external control to normalise RNA input. The Ct value is defined as the fractional cycle number at which the fluorescence passes the fixed threshold. The fold change was calculated using the $2^{-\Delta \Delta \mathrm{ct}}$ method, presented as the fold-expression change in dexamethasone-treated adipocytes relative to their corresponding control adipocytes after normalisation to the endogenous control. All experiments were performed in triplicate.

\section{Determination of protein expression}

One bottle $\left(25 \mathrm{~cm}^{2}\right)$ of frozen adipocytes was extracted with $1 \mathrm{ml}$ lysis buffer containing $100 \mathrm{mM} \mathrm{NaCl}, 2 \mathrm{mM}$ EDTA, 5\% SDS, $0.1 \mathrm{mM} \mathrm{Na}_{3} \mathrm{VO}_{4}, 50 \mathrm{mM} \mathrm{NaF}, 1 \mathrm{mM}$ benzamidine, $100 \mu \mathrm{M}$ AEBSF, $10 \mu \mathrm{g} / \mathrm{ml}$ aprotinin and $50 \mathrm{mM}$ HEPES ( $\mathrm{pH} 7.4$ ). The protein content was measured with the BCA Protein Assay Kit (Pierce 


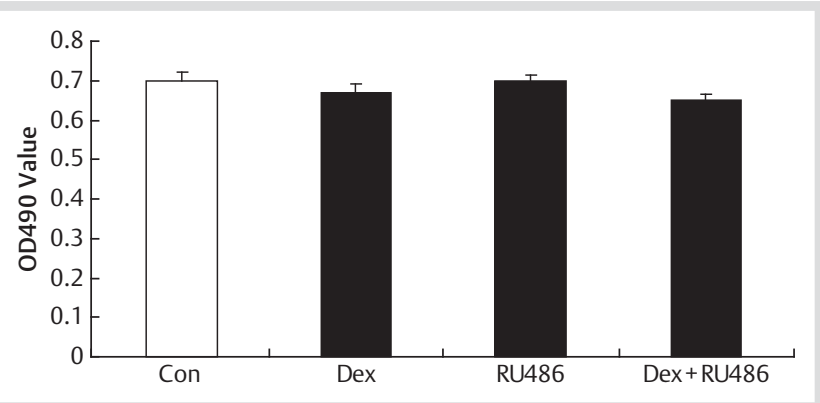

Fig. 1 Effect of $10^{-6} \mathrm{M}$ dexamethasone on proliferative activity of porcine preadipocytes. Con: control group; Dex: $10^{-6} \mathrm{M}$ dexamethasone group; RU486: $10^{-6} \mathrm{M}$ glucocorticoid receptor antagonist group; Dex+RU486: $10^{-6} \mathrm{M}$ dexamethasone and $10^{-6} \mathrm{M}$ glucocorticoid receptor antagonist group. $\mathrm{n}=6 /$ group.

biotechnology, Rockford, IL, USA). Forty micrograms of protein extract were mixed with loading buffer and denatured by boiling for $5 \mathrm{~min}$ before being loaded on a $10 \%$ SDS-polyacrylamide gel. After electrophoresis, the proteins were transferred to nitrocellulose membranes and blocked with 3\% BSA in Tween-Trisbuffered saline for $90 \mathrm{~min}$ at room temperature. After repeated washing with Tween-Tris-buffered saline, the membranes were incubated with the appropriate antibodies. Western blot analysis for detecting C/EBP- $\beta$ was performed with a polyclonal antibody (cs-150X, Santa Cruz Technology, CA, USA) at a dilution of $1: 1000$. C/EBP- $\beta$ was detected at $38 \mathrm{kDa}$. The PPAR- $\gamma$ antibody (Bioworld Technology, MN, USA) was used at a dilution of 1:500. A protein band at $57 \mathrm{kDa}$ was observed. An antibody against $\beta$-actin (Abcam, Cambridge, UK) was used as an internal standard at a 1:10000 dilution. Goat anti-rabbit IgG peroxidase-conjugated secondary antibodies (Bioworld Technology) were used at a dilution of 1:10000. Finally, the membrane was washed, and the specific signals were detected by chemiluminescence using the LumiGlo substrate (SuperSignalWest-PicoTrial Kit, Pierce, Rockford, IL, USA). The experiments were performed in triplicate.

\section{Plasmid construction}

Genomic fragments of porcine miR-374a/b and their precursors of approximately $89 \mathrm{bp}$ were synthesised by Invitrogen. There is one predicted conserved target site for miR-374a/b in the 3'-UTR of C/EBP- $\beta$ (www.targetscan.org). A $389 \mathrm{bp}$ fragment of the C/ EBP- $\beta$ 3'-UTR was amplified by PCR using the primers 5'-CCACAGTGACTCCGGGAAG-3' and 5'-CGTAGGAACATCTTTAAG CGA-3'. The $389 \mathrm{bp}$ fragment, which contains a motif for miR$374 \mathrm{a} / \mathrm{b}$ that is broadly conserved in vertebrates (www.tar getscan.org), was cloned downstream of the luciferase gene in the pGL3-Control luciferase reporter vector. These constructs, named pGL3-control/C/EBP- $\beta$, were transfected into HeLa cells. The PCR products were subcloned into the luciferase reporter pGL3-Control using Xbal (Invitrogen). Precursor miR-374a/b was annealed using annealing buffer $(5 \times)$, the miRNA precursor upstream sequence $(50 \mu \mathrm{M})$ and the downstream sequence $(50 \mu \mathrm{M})$. The $50 \mu \mathrm{l}$ reaction solutions were incubated in a 96-well optical plate at $95^{\circ} \mathrm{C}$ for $2 \mathrm{~min}$ and then subjected to touchdown PCR (with decreases of $0.1^{\circ} \mathrm{C} / 8 \mathrm{~s}$ until $25^{\circ} \mathrm{C}$ is reached); subsequently, the $\mathrm{PCR}$ products were subcloned into the pSilencer 3.0H1 siRNA expression vector using BamHI and HindIII (Invitrogen).

\section{DNA transfection}

Approximately $3 \times 10^{4} / \mathrm{cm}^{3} \mathrm{HeLa}$ cells were seeded and cultured in $25 \mathrm{~cm}^{2}$ cell culture bottles. When the cells reached $90-95 \%$ confluence, they were co-transfected with $100 \mathrm{ng}$ of pGL3control/C/EBP- $\beta$ 3'-UTR fluorescent luciferase reporter plasmid, $10 \mathrm{ng}$ of pRL-TK plasmid (used to normalise for transformation efficiency), or $100 \mathrm{ng}$ of pSilence $3.1 \mathrm{H} 1$-neo miR-374a/b with lipofectamine 2000 (Invitrogen) according to the manufacturer's instructions. Negative controls were co-transfected with $100 \mathrm{ng}$ of miR-SC, $100 \mathrm{ng}$ of target genes 3'-UTR fluorescent luciferase reporter plasmid and $10 \mathrm{ng}$ of pRL-TK plasmid. At the same time, the miRNA-374a/b inhibitor (Invitrogen) was added to the medium of the co-transfected cells. After transfection, the cells were counted, and the cell density was approximately $2 \times 10^{4} \mathrm{cells} / \mathrm{cm}^{3}$. The transfected HeLa cells were incubated at $5 \% \mathrm{CO}_{2}$ and $37^{\circ} \mathrm{C}$ for $24 \mathrm{~h}$.

\section{Dual luciferase activity assay}

Twenty-four hours after transfection, firefly and renilla luciferase activities were measured using a Dual-Luciferase Assay Kit (Promega) with a plate reader (PerkinElmer, Waltham, MA, USA). The renilla and firefly luciferase signals were detected using the Veritas Microplate Luminometer (Turner Biosystems, Sunnyvale, CA, USA). The firefly luciferase signal was normalised to the renilla luciferase signal. The normalised firefly luciferase activity was compared between miR-374a/b and the miRNA scrambled control (miR-SC) cells. The results were expressed as relative activity. Each target construct was tested in triplicate, and the assay was repeated to confirm the results.

\section{Statistical analysis}

All data are presented as the mean \pm SEM. Statistical analyses were carried out with Statistical Program for Social Sciences (SPSS) software 17.0 for Windows (SPSS Inc., Chicago, IL, USA). The differences were tested with a one-way ANOVA. A p-value of less than 0.05 was considered significant.

\section{Results}

\section{$\nabla$}

\section{Effect of $10^{-6} \mathrm{M}$ dexamethasone on the cell viability} and TG deposition of porcine preadipocytes ( 0 Fig. 1-3) As shown in $\odot$ Fig. 1, 10 $0^{-6} \mathrm{M}$ dexamethasone had no effect on the viability of porcine preadipocytes compared with the control group. The same concentration of RU486 showed no differences when compared with other 3 groups ( $p>0.05$ ).

Treatment with $10^{-6} \mathrm{M}$ dexamethasone for $48 \mathrm{~h}$ significantly increased the TG content when compared with the control group ( $\mathrm{p}<0.05$ ). However, treatment with only $10^{-6} \mathrm{M}$ RU486 or $10^{-6} \mathrm{M}$ RU486 together with $10^{-6} \mathrm{M}$ dexamethasone did not reverse the increased TG content induced by $10^{-6} \mathrm{M}$ dexamethasone.

\section{Effect of $10^{-6} \mathrm{M}$ dexamethasone on the expression of} target genes related to lipid metabolism

As shown in $\odot$ Fig. 4, the expression of PPAR- $\gamma$ and perilipin mRNA were significantly increased in the $10^{-6} \mathrm{M}$ dexamethasone group compared to the control group $(p<0.05)$. However, C/EBP- $\beta$ levels decreased significantly after $48 \mathrm{~h}$ treatment with $10^{-6} \mathrm{M}$ dexamethasone compared with the control group. GR and FAS mRNA expression was not significantly different between the groups $(p>0.05)$. 


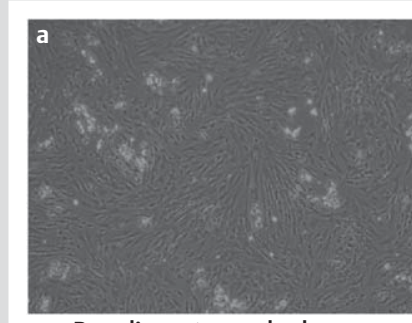

Preadipocyte reached more than $80 \%$ of the fusion $(200 \times)$

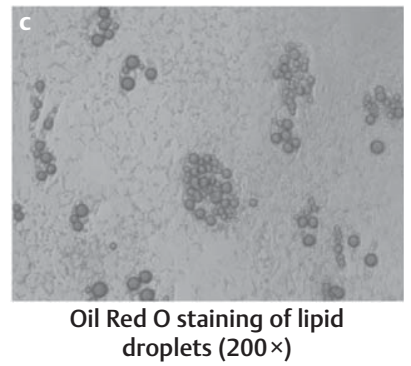

Fig. 2 Differentiation of pig primary adipocytes and Oil Red-O staining. a The preadipocytes merge more than $80 \%(\times 200)$. b Adipocyte differentiation for $48 \mathrm{~h}(\times 400)$. c Oil Red-O staining with adipocyte, the red parts are lipid droplets $(\times 200)$.

\section{Effect of $10^{-6} \mathrm{M}$ dexamethasone on PPAR-y and $\mathrm{Cl}$ EBP- $\beta$ protein expression}

PPAR- $\gamma$ protein level was significantly increased in the $10^{-6} \mathrm{M}$ dexamethasone group compared to the control group $(\mathrm{p}<0.05)$ ( $\odot$ Fig. 5a). However, C/EBP- $\beta$ protein levels were significantly decreased in the $10^{-6} \mathrm{M}$ dexamethasone group compared to the control group ( $\bullet$ Fig. 5b).

\section{Effect of $10^{-6} \mathrm{M}$ dexamethasone on the expression of miRNAs that targets the C/EBP- $\beta$ 3'-UTR}

As shown in 0 Fig. 6, miRNA-374 (miRNA-374a and miRNA$374 \mathrm{~b}$ ) expression in the $10^{-6} \mathrm{M}$ dexamethasone group was significantly increased $(\mathrm{p}<0.05)$ compared to the control group. However, miRNA-155, 362, 191, 455, and 423-5p expressions were not significantly different between the 2 groups.

\section{Validation of ssc-miR-374a and ssc-miR-374b targeting C/EBP- $\beta$ 3'-UTR}

miRNA-374a/b had highly conserved sites ( $\bullet$ Fig. 7a) for binding to the $3^{\prime}$-UTR of C/EBP- $\beta$. The miR-374a/b-targeted elements in the C/EBP- $\beta$ 3'-UTR are highly conserved in many mammals, including pig, human, mouse, rat, cow, sheep, chicken, and dog ( $\odot$ Fig. 7b). To ascertain whether miR-374a/b are able to recognise the C/EBP- $\beta 3$ '-UTR, we generated a luciferase reporter DNA construct containing the $389 \mathrm{bp}$ pig C/EBP- $\beta 3$ '-UTR with a putative miR-374a/b binding site and an ssc-miR-374a/b overexpression plasmid. When the pGL3-Control/C/EBP- $\beta$ 3'-UTR fluorescent luciferase reporter plasmid and the ssc-miR-374a/b overexpression vector were co-transfected into HeLa cells, luciferase activity was significantly suppressed by the ectopic expression of ssc-miR-374a/b after co-transfection for $24 \mathrm{~h}$. Though overexpression of ssc-miR-374a/b was able to significantly suppress luciferase activity after the addition of 50 or $100 \mathrm{ng}$ of miRNA-374a/b inhibitor, adding 150 or $200 \mathrm{ng}$ of miRNA-374a/b inhibitor could significantly reverse this suppression trend (० Fig. 8).

\section{Discussion}

$\nabla$

Glucocorticoids are important hormones involved in body metabolism. Regarding its influence on lipid metabolism, glucocorticoids have been proposed to have both adipogenic and lipolytic actions within adipose tissue [1-5]. Previous studies have demonstrated that glucocorticoids play a direct role in the formation of cytoplasmic lipid droplets $[27,28]$. The differentiation of 3T3-L1 preadipocytes can be induced by a 2-day treatment with a factor "cocktail" (DIM) containing synthetic dexamethasone, insulin, the phosphodiesterase inhibitor methylisobutylxanthine (IBMX), and fetal bovine serum [29]. In the present study, though preadipocyte cell viability was not different from the control group after treatment with $10^{-6} \mathrm{M}$ dexamethasone for $48 \mathrm{~h}$, yet the TG content was significantly increased [30]. The results indicated that $10^{-6} \mathrm{M}$ dexamethasone contributes to porcine preadipocyte differentiation and lipid droplet synthesis. Ru486 treatment did not reverse the increase of TG content induced by dexamethasone. In our preliminary experiment, $10^{-6} \mathrm{M}$ Ru486 can reverse the increase of TG content induced by $10^{-6} \mathrm{M}$ dexamethasone. However, in the current experiment, the inhibitor demonstrated no effect. The reason may be due to the chemical problem of Ru486 or the pooled preadipocytes from five 35-day Meishan piglets. Therefore, in the late analysis only control and dexamethasone groups were used.

Preadipocytes that gradually filled with lipid droplets and differentiated into mature fat cells with a single chamber were regulated by a number of transcription factors, including C/EBPs and PPAR- $\gamma$. The overexpression of PPAR- $\gamma$ can promote adipogenesis [31,32]. Compared to wild-type controls, heterozygous PPAR- $\gamma$-deficient mice show decreased fat mass [17]. In the current study, PPAR- $\gamma$ mRNA and protein expression was significantly upregulated after treatment with $10^{-6} \mathrm{M}$ dexamethasone for $48 \mathrm{~h}$. This finding is consistent with previous reports demonstrating that dexamethasone induces preadipocyte recruitment and increases PPAR- $\gamma$ protein expression in porcine stromal-vascular (S-V) cells [6]. The perilipins are the most abundant proteins at the surfaces of lipid droplets in adipocytes, which play a role in regulating the packaging and storage of neutral lipids [33-35]. Further studies have shown that PPAR- $\gamma$ is an important transcriptional factor for perilipin, and the upstream sequence of the perilipin promoter contains a PPRE. Previous studies have shown that treating differentiated 3T3-L1 adipocytes with a PPAR- $\gamma$ agonist significantly augments perilipin mRNA expression $[36,37]$. In the current study, perilipin mRNA expression was significantly increased in the $10^{-6} \mathrm{M}$ dexamethasone treatment group compared to the control group.

C/EBP- $\beta$ plays an important role in the induction of PPAR- $\gamma$ expression and adipogenesis. Wiper-Bergeron showed that glucocorticoid-stimulated preadipocyte differentiation is mediated through the acetylation of C/EBP- $\beta$ [38]. C/EBPs family includes 6 kinds of transcription factors, and C/EBP- $\alpha, C / E B P-\beta, C / E B P-\delta$, and $\mathrm{C} / \mathrm{EBP}-\zeta$ can expressed in adipose tissue [39]. Expression of various transcription factors in adipocyte differentiation process has a time sequence. In the current study, C/EBP- $\beta$ expression significantly decreased after 48 -h treatment with $10^{-6} \mathrm{M}$ dexamethasone. Previous studies have shown that the expression of C/EBP- $\beta$ usually occurs at a very early stage of adipocyte differentiation, which is followed by the induction of C/EBP- $\alpha$ and PPAR- $\gamma$, which promotes differentiation by activating adipose-specific gene expression $[40,41]$. These results show that there is a time difference between PPAR- $\gamma$ and C/EBP- $\beta$ expression. When the adipose 


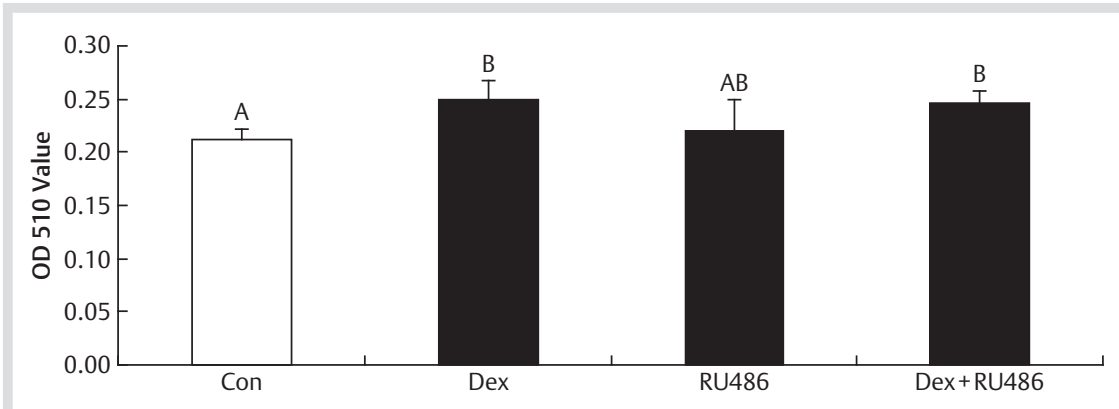

Fig. 3 Effect of $10^{-6} \mathrm{M}$ dexamethasone on triglyceride deposition of primary cultured adipocyte. Con: control group; Dex: $10^{-6} \mathrm{M}$ dexamethasone group; RU486: $10^{-6} \mathrm{M}$ glucocorticoid receptor antagonist group; Dex+RU486: $10^{-6} \mathrm{M}$ dexamethasone and $10^{-6} \mathrm{M}$ glucocorticoid receptor antagonist group. Different letter means significant difference, $p<0.05, n=6 /$ group.

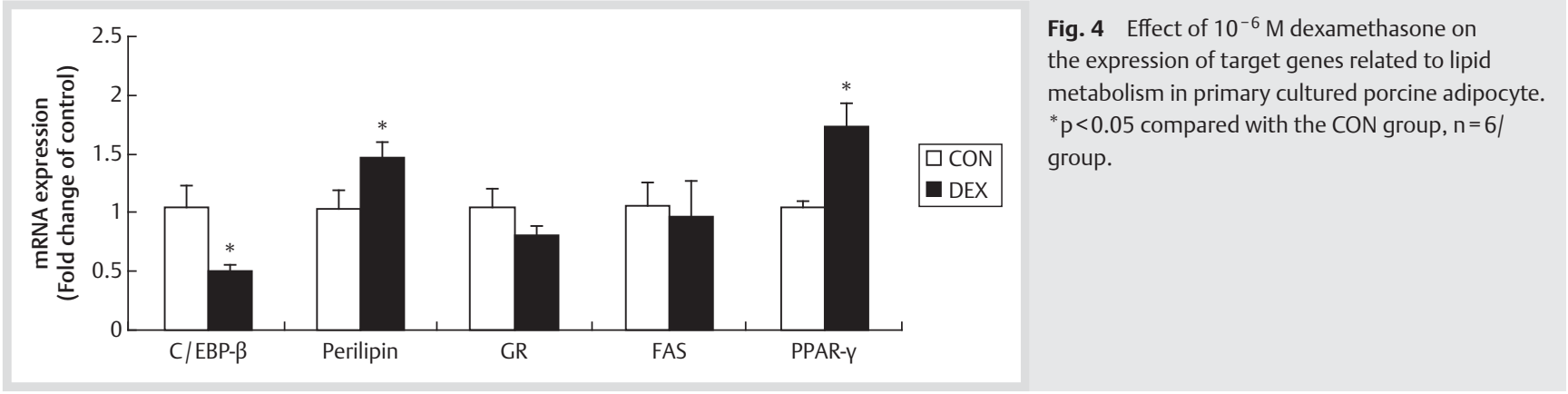

differentiation process progresses, C/EBP- $\beta$ expression shows a declining trend, while PPAR- $\gamma$ expression gradually increases [42]. Therefore, the present results illustrate that after treatment with $10^{-6} \mathrm{M}$ dexamethasone for $48 \mathrm{~h}$, the differentiation of porcine preadipocytes has reached a late stage of differentiation.

It is largely unknown which factors induce the C/EBP- $\beta$ expression decrease as the adipose differentiation process progresses. In recent years, it has been shown that miRNAs are involved in the regulatory network of many biological processes through the post-transcriptional regulation of transcription factors. Several miRNAs were reported to be expressed in mammalian adipocytes and seem to play a role in the regulation of adipogenesis [15]. In the present study, we identified seven candidates of C/EBP- $\beta$-targeting miRNAs by bioinformatic analyses. Among the predicated miRNAs, only miRNA-374a and miRNA-374b were found to be upregulated in the $10^{-6} \mathrm{M}$ dexamethasone treatment cells. In the previous study, miRNA-374a/b was reported to serve as a prognostic marker for patient risk stratification at early stages of non-small cell lung cancer progression [43], and miR-374 has also been found to respond to primary infections of self-healing Plasmodium chabaudi malaria in female C57BL/6 mice [44]. miR-374a could be involved in the phospho$\Delta \mathrm{Np} 63 \alpha$-dependent regulation of autophagic signalling and the control cell death of squamous cell carcinoma (SCC) cells [45]. The upregulation of miR-374a is thought to participate in the carcinogenesis of the colon without lymph node metastasis [46]. miR-374b expression in seminal plasma could also provide a novel, noninvasive approach for diagnosing male infertility [47]. Referring to the role of miR-374 in the lipid metabolism, our previously reports demonstrated that microRNA-374b mediate the effect of maternal dietary protein on offspring lipid metabolism in Meishan pigs by targeting on the C/EBP- $\beta$ [48]. In the present study, both microRNA-374b and microRNA-374a were shown to participate in the regulation of adipocyte differentiation. Luciferase reporter assays were performed to fully validate the predicted miRNA-mRNA interactions. In the present study, miR-374a/b overexpression significantly reduced the activity of a luciferase reporter containing the C/EBP- $\beta$ 3'-UTR after co-

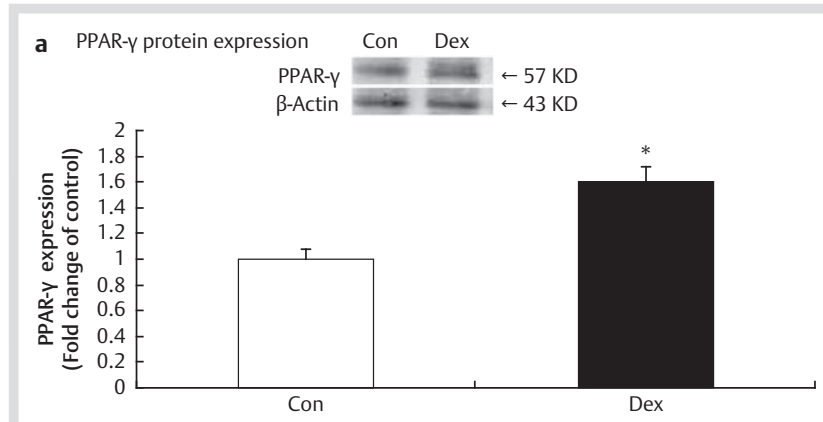

b C/EBP- $\beta$ protein expression Con Dex
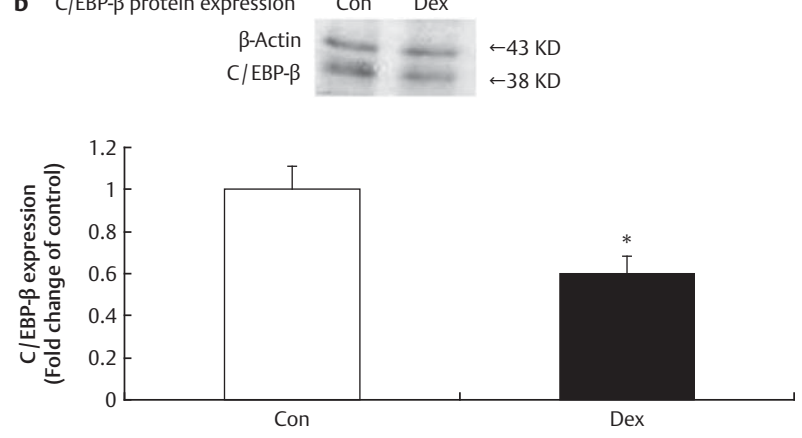

Fig. 5 Effect of dexamethasone on PPAR- $y$ and C/EBP- $\beta$ protein expression in primary cultured porcine adipocyte. a PPAR-y. $\mathbf{b} C / E B P-\beta .{ }^{*} p<0.05$ compared with the CON group, $n=6 /$ group.

transfection for $24 \mathrm{~h}$, and a miRNA-374a/b inhibitor could significantly reverse this suppression. These results indicate that miR-374a/b can directly recognise and bind to the 3'-UTR of C/EBP- $\beta$ and suppress C/EBP- $\beta$ expression. In contrast, miR$374 \mathrm{a} / \mathrm{b}$ did not alter the activity of a luciferase reporter that has no C/EBP- $\beta$ 3'-UTR (data not shown).

In conclusion, the present study showed that treatment with $10^{-6} \mathrm{M}$ dexamethasone promoted lipid accumulation in primary porcine preadipocytes. The expression response of PPAR- $\gamma$ and C/EBP- $\beta$ was different after 48 -h treatment. miR-374a/b may be involved in the decrease of $C / E B P-\beta$ expression. Though 


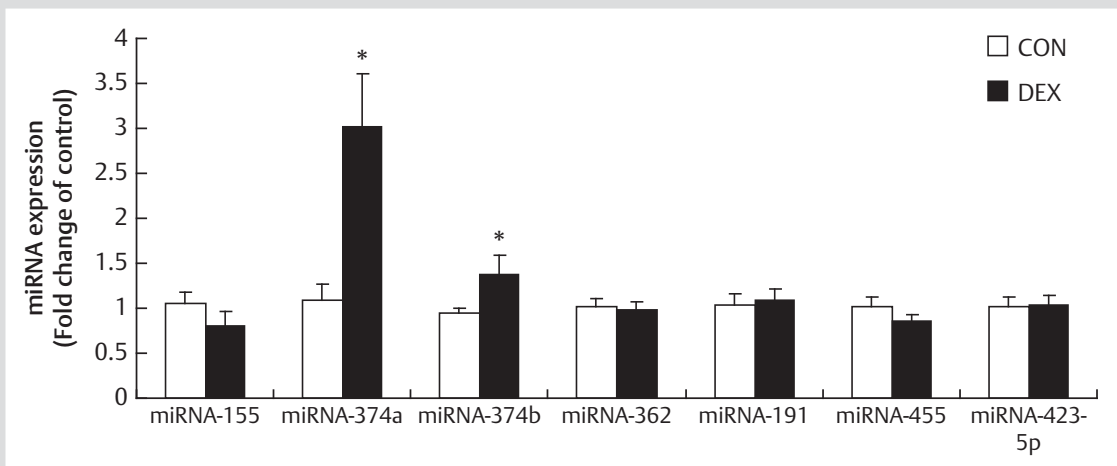

\section{a Conserved}

Position 484-490 of C/EBP- $\beta$ 3'-UTR 5' ...GUAAUUUUAAUAUUU UAUUAUAU... ssc-miR-374a/b 3'... GUGAAUCGUCCAACAUAAUAUA...

b

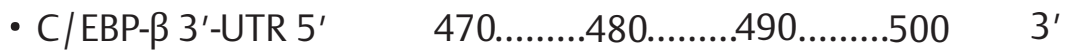

- Ss UUUUUUGUauUauaAaAaAuAauc

- Hs UUUUUUGUaUUAUAAAAAAU--Aa

- $\mathrm{Mm}$

- Ec

- Rn

- Gg

- ssc-miR-374a/b seed 3' AUAAUAU 5' UUUUUUGUAUUAUAAAAAAUA-GU UUUUUUGUAUUAUAAAAAAU-AA UUUUUUGUAUUAUAAAAAAA-GU UUUUUUGUAUUAUAAAGAA U-AAU
Fig. 6 Effect of dexamethasone on adipocyte miRNAs expression target $C / E B P-\beta$ of primary cultured adipocyte at weaning pigs. Values are represented as means \pm SEM, ${ }^{*} p<0.05$ compared with the CON group, $n=6 /$ group.

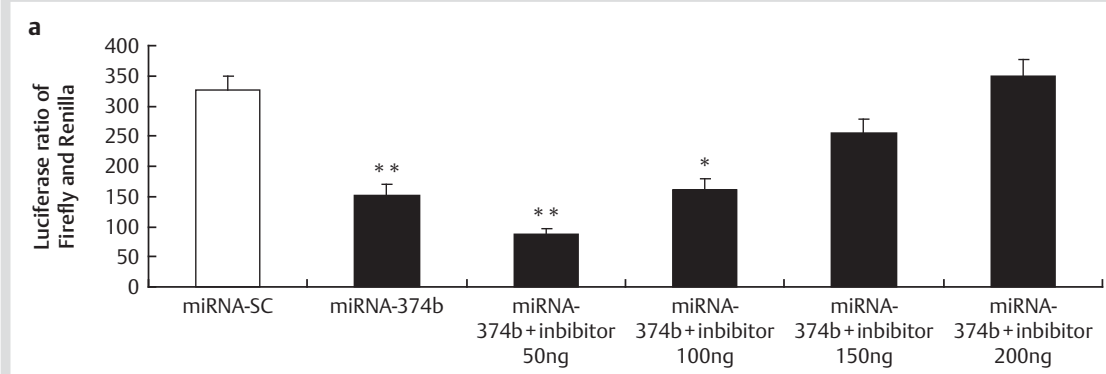

Fig. 7 The miR-374a/b target site in the $3^{\prime}$-UTR of C/EBP- $\beta$. a The predicted conserved binding site of miR-374a/b in the $3^{\prime}$-UTR of pig C/EBP- $\beta$. $\mathbf{b}$ Conservation of the miR-374a/b binding region in the C/EBP- $\beta 3$ 3'-UTR among mammals. The miR-374a/b seed match is highlighted in red (TargetScan). Ss: pig; Hs: human; Mm: mouse; Ec: horse; Bt: cow; Rn: rat; Gg: chicken.

b

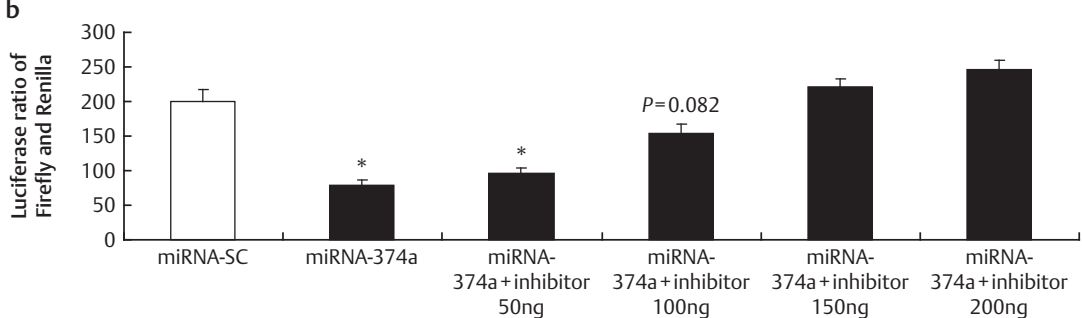

Fig. 8 Validation of ssc-miR-374a/b targeting of the C/EBP- $\beta 33^{\prime}-U T R$ at $24 \mathrm{~h}$ after transfection. a Validation of ssc-miR-374b targeting of the $\mathrm{Cl}$ EBP- $\beta$ 3'-UTR. $\mathbf{b}$ Validation of ssc-miR-374a targeting of the C/EBP- $\beta 3^{\prime}-$ UTR. ${ }^{*} p<0.05$ compared with the miRNA-SC group and ${ }^{* *} \mathrm{p}<0.01$ compared with the miRNA-SC group, $n=3 /$ group.

the reason why miR-374a/b increased during adipocyte maturation still needs further study. These results provide a possibly new target for the regulation of porcine fat deposition.

\section{Acknowledgements}

This study was supported by the National Basic Research Program of China (2012CB124703), the Special Fund for Agro-scientific Research in the Public Interest (201003011), the Major National Science \& Technology Projects of China (2009ZX08009-
138B), the Fundamental Research Funds for the Central Universities (KYZ200913), and the Priority Academic Program Development of Jiangsu Higher Education Institutions.

\section{Conflict of Interest}

The authors declare that they have no conflicts of interest in the authorship or publication of this contribution. 


\section{References}

1 Peckett AJ, Wright DC, Riddell MC. The effects of glucocorticoids on adipose tissue lipid metabolism. Metabolism 2011; 60: 1500-1510

2 Djurhuus CB, Gravholt CH, Nielsen S, Mengel A, Christiansen JS, Schmitz OE, Moller N. Effects of cortisol on lipolysis and regional interstitial glycerol levels in humans. Am J Physiol Endocrinol Metab 2002; 283: E172-E177

3 Krsek M, osicka MR, Nedvidkova J, Kvasnickova H, Hana V, Marek J, Haluzik $M$, Lai EW, Pacak $K$. Increased lipolysis of subcutaneous abdominal adipose tissue and altered noradrenergic activity in patients with Cushing's syndrome: an in-vivo microdialysis study. Physiol Res 2006; 55: 421-428

4 Wiper-Bergeron N, Wu D, Pope L, Schild-Poulter C, Hache RJ. Stimulation of preadipocyte differentiation by steroid through targeting of an HDAC1 complex. EMBO J 2003; 22: 2135-2145

5 Caprio M, Feve B, Claes A, Viengchareun S, Lombes M, Zennaro MC. Pivotal role of the mineralocorticoid receptor in corticosteroid-induced adipogenesis. FASEB J 2007; 21: 2185-2194

6 Hausman GJ. Dexamethasone induced preadipocyte recruitment and expression of CCAAT/enhancing binding protein alpha and peroxisome proliferator activated receptor-gamma proteins in porcine stromal-vascular $(\mathrm{S}-\mathrm{V})$ cell cultures obtained before and after the onset of fetal adipogenesis. Gen Comp Endocrinol 2003; 133: 61-70

7 Hausman GJ. The influence of dexamethasone and insulin on expression of CCAAT/enhancer binding protein isoforms during preadipocyte differentiation in porcine stromal-vascular cell cultures: evidence for very early expression of C/EBPalpha. J Anim Sci 2000; 78: 1227-1235

8 Zhang H, Wu J, Wang B, Lu Z, Yang G. Regulation of SOCS-3, OB, GLUT4 and PPARgamma gene expression by insulin and dexamethasone in porcine primary adipocyte. Sheng Wu Gong Cheng Xue Bao 2008; 24: $1354-1360$

9 Romao JM, Jin W, Dodson MV, Hausman GJ, Moore SS, Guan le L. MicroRNA regulation in mammalian adipogenesis. Exp Biol Med (Maywood) 2011 ; 236: 997-1004

10 Lefterova MI, Lazar MA. New developments in adipogenesis. Trends Endocrinol Metab 2009; 20: 107-114

11 Blanchette-Mackie EJ, Dwyer NK, Barber T, Coxey RA, Takeda T, Rondinone CM, Theodorakis JL, Greenberg AS, Londos C. Perilipin is located on the surface layer of intracellular lipid droplets in adipocytes. J Lipid Res 1995; 36: 1211-1226

12 Cai Y, Yu X, Hu S, Yu J. A brief review on the mechanisms of miRNA regulation. Genomics Proteomics Bioinformatics 2009; 7: 147-154

13 Chua JH, Armugam A, Jeyaseelan K. MicroRNAs: biogenesis, function and applications. Curr Opin Mol Ther 2009; 11: 189-199

14 Davis-Dusenbery BN, Hata A. Mechanisms of control of microRNA biogenesis. J Biochem 2010; 148: 381-392

15 Xu P, Vernooy SY, Guo M, Hay BA. The Drosophila microRNA Mir-14 suppresses cell death and is required for normal fat metabolism. Curr Biol 2003; 13: 790-795

16 Huang $Y$, Cai $X, \mathrm{Hu} Y$. The important role of microRNAs in lipid metabolism. Metabolism 2012; 62: e1-e2

17 Nakanishi $N$, Nakagawa $Y$, Tokushige $N$, Aoki N, Matsuzaka T, Ishii $K$ Yahagi N, Kobayashi K, Yatoh S, Takahashi A, Suzuki H, Urayama O, Yamada N, Shimano $H$. The up-regulation of microRNA-335 is associated with lipid metabolism in liver and white adipose tissue of genetically obese mice. Biochem Biophys Res Commun 2009; 385: 492-496

18 Bai L, Pang WJ, Yang YJ, Yang GS. Modulation of Sirt1 by resveratrol and nicotinamide alters proliferation and differentiation of pig preadipocytes. Mol Cell Biochem 2008; 307: 129-140

$19 \mathrm{Li}$ B, Zerby HN, Lee K. Heart fatty acid binding protein is upregulated during porcine adipocyte development. J Anim Sci 2007; 85: 1651-1659

20 Wang T, Li M, Guan J, Li P, Wang H, Guo Y, Shuai S, Li X. MicroRNAs miR-27a and miR-143 Regulate Porcine Adipocyte Lipid Metabolism. Int J Mol Sci 2011; 12: 7950-7959

21 Ramírez-Zacarías JL, Castro-Muñozledo F, Kuri-Harcuch W. Quantitation of adipose conversion and triglycerides by staining intracytoplasmic lipids with Oil red O. Histochem 1992; 97: 493-497

22 Dionisi M, Alexander SP, Bennett AJ. Oleamide activates peroxisome proliferator-activated receptor gamma (PPARY) in vitro. Lipids Health Dis 2012; 11: 51

23 Krek A, Grun D, Poy MN, Wolf R, Rosenberg L, Epstein EJ, MacMenamin P, da Piedade I, Gunsalus KC, Stoffel M, Rajewsky N. Combinatorial microRNA target predictions. Nat Genet 2005; 37: 495-500

24 John B, Enright AJ, Aravin A, Tuschl T, Sander C, Marks DS. Human MicroRNA targets. PLoS Biol 2004; 2: e363
25 Lewis $B P$, Burge $C B$, Bartel DP. Conserved seed pairing, often flanked by adenosines, indicates that thousands of human genes are microRNA targets. Cell 2005; 120: 15-20

26 Shi $R$, Chiang VL. Facile means for quantifying microRNA expression by real-time PCR. Biotechniques 2005; 39: 519-525

27 Mendoza-Figueroa T, Hernandez A, De Lourdes Lopez M, Kuri-Harcuch $W$. Intracytoplasmic triglyceride accumulation produced by dexamethasone in adult rat hepatocytes cultivated on 3T3 cells. Toxicology 1988; 52: 273-286

28 Wu CH, Chien HF, Chang CY, Chen SH, Huang YS. Response of amoeboid and differentiating ramified microglia to glucocorticoids in postnatal rats: a lectin histochemical and ultrastructural study. Neurosci Res 2001; 40: 235-244

29 Pantoja C, Huff JT, Yamamoto KR. Glucocorticoid signaling defines a novel commitment state during adipogenesis in vitro. Mol Biol Cell 2008; 19: 4032-4041

30 Mendoza FT, Hernandez A, De LLM, Kuri HW. Intracytoplasmic triglyceride accumulation produced by dexamethasone in adult rat hepatocytes cultivated on 3T3 cells. Toxicology 1988; 52: 273-286

31 Barak Y, Nelson MC, Ong ES, Jones YZ, Ruiz-Lozano P, Chien KR, Koder A, Evans RM. PPAR gamma is required for placental, cardiac, and adipose tissue development. Mol Cell 1999; 4: 585-595

32 Rosen ED, Sarraf P, Troy AE, Bradwin G, Moore K, Milstone DS, Spiegelman BM, Mortensen RM. PPAR gamma is required for the differentiation of adipose tissue in vivo and in vitro. Mol Cell 1999; 4: 611-617

33 Bickel PE, Tansey JT, Welte MA. PAT proteins, an ancient family of lipid droplet proteins that regulate cellular lipid stores. Biochim Biophys Acta 2009; 1791: 419-440

$34 \mathrm{Liu} M F, \mathrm{Xu} \mathrm{GH}$. Function of PAT family proteins in the lipid metabolism. Sheng Li Ke Xue Jin Zhan 2006; 37: 103-107

35 Yamaguchi T. PAT family: lipid droplet-associated proteins that regulate fat storage and lipolysis. Seikagaku 2007; 79: 162-166

36 Arimura $N$, Horiba $T$, Imagawa $M$, Shimizu $M$, Sato $R$. The peroxisome proliferator-activated receptor gamma regulates expression of the perilipin gene in adipocytes. J Biol Chem 2004; 279: 10070-10076

37 Nagai S, Shimizu C, Umetsu M, Taniguchi S, Endo M, Miyoshi H, Yoshioka $N$, Kubo M, Koike T. Identification of a functional peroxisome proliferator-activated receptor responsive element within the murine perilipin gene. Endocrinology 2004; 145: 2346-2356

38 Wiper-Bergeron N, Salem HA, Tomlinson JJ, Wu D, Hache RJ. Glucocorticoid-stimulated preadipocyte differentiation is mediated through acetylation of C/EBPbeta by GCN5. Proc Natl Acad Sci USA 2007; 104: $2703-2708$

39 Rangwala SM, Lazar MA. Transcriptional control of adipogenesis. Annu Rev Nutr 2000; 20: 535-559

40 Yeh WC, Cao Z, Classon M, McKnight SL. Cascade regulation of terminal adipocyte differentiation by three members of the C/EBP family of leucine zipper proteins. Genes Dev 1995; 9: 168-181

41 Rosen ED. The transcriptional basis of adipocyte development. Prostaglandins Leukot Essent Fatty Acids 2005; 73: 31-34

42 Tomlinson JJ, Boudreau A, Wu D, Atlas E, Hache RJ. Modulation of early human preadipocyte differentiation by glucocorticoids. Endocrinology 2006; 147: 5284-5293

43 Vosa U, Vooder T, Kolde R, Fischer $K$, Valk $K$, Tonisson N, Roosipuu $R$ Vilo J, Metspalu A, Annilo T. Identification of miR-374a as a prognostic marker for survival in patients with early-stage nonsmall cell lung cancer. Genes Chromosomes Cancer 2011; 50: 812-822

44 Delic D, Dkhil M, Al-Quraishy S, Wunderlich F. Hepatic miRNA expression reprogrammed by Plasmodium chabaudi malaria. Parasitol Res 2011; 108: 1111-1121

45 Huang Y, Guerrero-Preston R, Ratovitski EA. Phospho-DeltaNp63alphadependent regulation of autophagic signaling through transcription and micro-RNA modulation. Cell Cycle 2012; 11: 1247-1259

46 Wang YX, Zhang XY, Zhang BF, Yang CQ Chen XM, Gao HJ. Initial study of microRNA expression profiles of colonic cancer without lymph node metastasis. J Dig Dis 2010; 11: 50-54

47 Wang C, Yang C, Chen X, Yao B, Zhu C, Li L, Wang J, Li X, Shao Y, Liu Y, Ji $J$, Zhang J, Zen $K$, Zhang CY, Zhang C. Altered profile of seminal plasma microRNAs in the molecular diagnosis of male infertility. Clin Chem 2011: 57: 1722-1731

48 Pan S, Zheng Y, Zhao R, Yang X. MicroRNA-130b and microRNA-374b mediate the effect of maternal dietary protein on offspring lipid metabolism in Meishan pigs. Br J Nutr 2012; 1-8 